\title{
El estilo de una corte: apuntes sobre Virgilio Malvezzi y el laconismo hispano
}

\author{
Jorge García López \\ Universitat de Girona \\ jorge.garcia@udg.es
}

\section{Resumen}

Virgilio Malvezzi fue autor italiano de gran éxito en la corte de Felipe IV a partir de la traducción de su biografía clásica Il Romulo (1629) por Francisco de Quevedo en 1632, pasando a convertirse en uno de los modelos de la prosa lacónica en castellano. Autores cortesanos como el mismo Quevedo o Diego de Saavedra Fajardo escribirán sus obras de carácter político en la prosa lacónica y concentrada que pone de moda Il Romulo, y su influencia se puede seguir incluso en autores secundarios como Mártir Rizo. Asimismo, en autores que comienzan a escribir a mediados o finales de la década de los años treinta del siglo XVII, cuyo ejemplo fundamental es Baltasar Gracián, que con sus tres obras menores (El héroe, El discreto y El político) muestra la influencia de ese nuevo estilo cortesano, si bien, desde un principio, con un grado de elaboración y refinamiento excepcional, que lo llevarán a convertirse en el ejemplo clásico del estilo lacónico.

Palabras clave: Malvezzi, lenguaje político, siglo XVI, Quevedo, Saavedra Fajardo, Mártir Rizo, Gracián.

\section{Abstract}

Virgilio Malvezzi was a greatly successful Italian author in the court of Filipe IV following the classic biographical translation of Il Romulo (1629) into Spanish by Francisco de Quevedo in 1632, becoming one of the models of laconic prose in Castilian. Court authors like Quevedo or Diego de Saavedra Fajardo wrote their political works in laconic prose in the fashion of Il Romulo, and its influence can be seen in secondary authors like Mártir Rizo as well as authors beginning to write by the middle to late 1630's. A fundamental example is Baltasar Gracián who, with his three minor works (El héroe, El discreto and $E l$ politico), fully demonstrates the new courtesan style with a degree of elaborate and exceptional refinement and emerges as a classic example of the laconic style.

Key words: Malvezzi, Political language, 16th Century, Quevedo, Saavedra Fajardo, Mártir Rizo, Gracián. 
Para Carlos Vaíllo, amigo y maestro.

Italia y España forman durante el siglo XVI y buena parte del XVII una suerte de comunidad cultural que se extiende a lo largo de un mar y dos penínsulas. Los españoles de la época, desde Herrera hasta Saavedra Fajardo, fueron profundamente conscientes de ello, y teorizaron esa relación bajo el conocido tópico de las armas y las letras, aunque entendido de forma diferente en cada orilla. Un puñado bien largo de escritores auriseculares serían en verdad del todo incomprensibles sin ahondar en esa relación. En las páginas que siguen esbozaremos un ejemplo en la obra de Virgilio Malvezzi, brillante astro de la literatura europea de su tiempo, como atestigua la rápida difusión de su obra en la Europa de mediados del siglo XVII. ${ }^{1}$ Fue a la vez resultado y víctima de esa relación histórica, y, con posterioridad, en la perspectiva de clasicismos posteriores, apenas recordado como maestro de una errática anacronía. ${ }^{2}$

Sin embargo, la mera inmersión en la literatura política, tan del gusto de esos años centrales del siglo XVII, revela el apego manifiesto y sorprendente a las obras del marqués de Malvezzi. Y esto hasta el punto de que podemos considerarlo como introductor del estilo lacónico en la corte de Felipe IV a partir de su obra Il Romulo (1629). Su filiación intelectual y literaria parece clara desde sus Discorsi sopra Cornelio Tacito (Venecia, Marco Ginami, 1622) ${ }^{3}$ y descuella con posterioridad en obras cortesanas como Il ritratto del privato politico cristiano (Bolonia, Giacomo Monti, 1635). ${ }^{4}$ Sin embargo, lo que en esencia nos interesa ahora son sus biografías históricas de cuño lacónico, como Il Romulo (Bolonia, Clemente Ferroni, 1629), ${ }^{5}$ casi inmediatamente traducido al castellano por Quevedo, ${ }^{6}$ Il Tarquinio superbo (Bolonia, Clemente Ferroni, 1632) ${ }^{7}$ y Davide perseguitato (Bolonia, Giacomo Monti, 1634). Su disposición literaria es harto simple. Una serie de datos espigados en fuentes históricas o bíblicas conforman un tenue hilo argumental que pone de manifiesto

1. Aunque poco frecuentado, su importancia es evidente desde Benedetto Croce, Nuovi Saggi nella letteratura italiana del Seicento, Bari: Laterza, 1949, p. 95-109 y Ezio RAIMONDI, Letteratura Barocca. Studi sul Seicento italiano, Firenze: Leo S. Olschki, 1982. Véase también Marc Fumaroli, L'âge de l'eloquence. Rhétorique et "res literaria" de la Renaissance au seuil de l'epoque classique, Genève: Droz, 1980 y Beatriz ANTÓN, El tacitismo en el siglo XVII en España. El proceso de "receptio», Valladolid: Universidad de Valladolid, 1991, por ejemplo p. 117-120. Aportación de conjunto sobre la vida y obra del marqués Virgilio Malvezzi lo constituye el libro de Rodolfo BraENDLI, Virgilio Malvezzi, politico y moralista, Basilea, 1964, y véase también Silvia BullETA, «Etica, retorica e "dramma" politico nelle storie romane di Virgilio Malvezzi», Studi secenteschi, n. XXXVI, 1995, p. 4-67.

2. Marc FuMAROLI, op. cit., p. 217-219.

3. Tommaso BozZA, Scrittori politici italiani dal 1550 al 1650, Roma: Edizioni di Storia e Letteratura, 1980, p. 140 [1940].

4. Véase Virgilio MALVEZZI, Il ritratto del privato politico cristiano, ed. de Maria Luisa DoGLIO, Palermo: Sellerio, 1993.

5. Tommaso BOZZA, op. cit., p. 163-164.

6. Francisco De Quevedo, El Rómulo, ed. de Carmen Isasi, Bilbao: Universidad de Deusto, 1993.

7. Tommaso BozzA, op. cit., p. 168-169. 
acontecimientos y decisiones: la prosa lacónica hará el resto, deduciendo o discutiendo lecciones morales y políticas de tales actos. Con las dos primeras, y menos con la tercera, nuestro marqués parece convertirse en oráculo de su época, lo que explica la notable acumulación de ediciones italianas y traducciones a lo ancho de Europa. Bien podemos preguntarnos por la razón de tal éxito, hilvanando así la madeja del gusto estético del período.

Se suele considerar la obra de Virgilio Malvezzi como ejemplo máximo del estilo lacónico en el siglo XVII, en el intento de hallar una alternativa retórica al ciceronianismo. Exponente e impulsor de ese estilo en latín será Justo Lipsio en la segunda mitad del siglo XVI, tanto en sus ediciones de Séneca como de Cornelio Tácito, y en sus propias obras latinas: una influencia que se dilata a lo largo de la centuria siguiente; Quevedo, por citar un ejemplo paradigmático, se nos muestra cercano seguidor de la obra literaria y filosófica de Justo Lipsio, ${ }^{8}$ y no sólo por las epístolas latinas de juventud cruzadas con el maestro. También Herycius Puteanus, discípulo de Lipsio, propugna y teoriza la oscuridad lacónica como norma del estilo en su De laconismo syntagma (1609). ${ }^{9} \mathrm{El}$ laconismo se opone el asianismo retórico de la poesía seicentista, un estilo que solemos identificar con la poesía de Góngora, de amplio éxito a lo largo del siglo XVII. Baltasar Gracián nos detalla con equilibrada simplicidad la diferencia entre ambos estilos en el discurso LXI de su Agudeza y arte de ingenio: «Descendiendo a los estilos en su hermosa variedad, dos son los capitales, redundante el uno, y conciso el otro, según su esencia: asiático y lacónico, según la autoridad. Yerro sería condenar cualquiera, porque cada uno tiene su perfección y su ocasión. El dilatado es propio de oradores; el ajustado de filósofos morales». ${ }^{10}$ Sin embargo, la identificación de Malvezzi con el estilo lacónico está lejos de limitarse a la categoría de mero ejemplo brillante. Corre por la prosa de Virgilio Malvezzi un acierto profundo en la síntesis de elementos hermanos, pero hasta entonces inconexos, que confiere soltura al nuevo estilo y le concede la equilibrada plenitud del clasicismo. Veámoslo con algún detalle.

Para empezar, el marqués acertó a reunir en Il Romulo una multitud de cuestiones que hacían las delicias del momento. Podía verse en esta obra, por ejemplo, la versión clásica de mitos cristianos, como el de Caín y Abel, verificando de paso una fatal contradicción entre necesidad política y valores éticos que sustenta el atormentado pensamiento político de esas décadas iniciales del siglo XVII. Venía también a entroncar con la historia de Roma y lo que ella significaba para el pensamiento político como ciudad modelo de la reflexión teórica, tanto en la obra de Livio, más cercana a los tratadistas del quinientos (y al mismo Machiavelli), como en el admirado Tácito. Enlazaba, en fin, fácil-

8. Henry Etinghausen, Francisco de Quevedo and the Neoestoic Movement, Oxford: Oxford University Press, 1972 y véase ahora Lía SCHWARTZ, "Justo Lipsio en Quevedo: neoestoicismo, política y sátira» (en prensa).

9. Véase n. 39 para su relación con Saavedra FAJARDO.

10. Baltasar Gracián, Agudeza y arte de ingenio, ed. de Evaristo Correa, Madrid: Castalia, II, p. 235-236. 
mente con la Política de Aristóteles, que tiene en la ciudad el centro de reflexión y base de su antropología. No era poco. La biografía lacónica se revelaba, en suma, como un medio eficaz de síntesis de las perspectivas esenciales del discurso político renacentista.

A ello se unía el planteamiento estilístico. Si ya por sus perfiles temáticos condensaba una serie visible de centros de interés en la época, el marqués de Malvezzi acertaba a tratar esos temas en romance con la misma desenvoltura con que Cornelio Tácito lo había hecho en latín, pero ya no para dar forma a una farragosa historia antigua o moderna, sino para enlazarlo con una biografía que tiene la brevitas por norma. De esta forma, convergían en su prosa romance los ecos de una serie de obras que conformaban los modelos admirados de la prosa latina desde las últimas décadas del siglo XVI. En sus escritos se fundían con naturalidad y confluían singularmente la brevedad de Plinio, la reflexión moral de Séneca o la política de Tácito. De hecho, la prosa de Tácito inundaba la biografía seicentista, recogiendo la exigencia de la brevedad expositiva, ya enunciada por Machiavelli en el prólogo al Principe como aneja al discurso político, y por tanto moral. Se alcanzaba así un interesante resultado donde la brevedad destilaba una suerte de quintaesencia del comportamiento cívico, renovando y revitalizando el biografismo histórico o clásico. Como recuerda Baltasar Gracián en su Agudeza y arte de ingenio, el brillante marqués "no tiene palabra que no encierre un alma, todo es viveza y espíritu». ${ }^{11}$

Aquí vale recordar que tanto la obra de Cornelio Tácito, como el estilo que supone, se han postulado como pujantes herederos de la posteridad del Principe. La obra de Machiavelli marcó un punto de inflexión en el pensamiento político occidental, y no hace falta recordar que, desde el Concilio de Trento, se convirtió en su totalidad en objeto de anatema. Sin embargo, ninguna época puede escapar a los problemas que constituyen la base de su sentido: si no se podía nombrar en público a Niccolò Machiavelli, bastaba buscar un sustituto a la altura de sus posibilidades, y éste se encontró en Tácito convenientemente reinterpretado a tal efecto. ${ }^{12}$ Sea cual fuere el alcance histórico de tal interpretación, la impronta de Machiavelli parece innegable en el origen del Romulo, que se anuncia como la primera de una serie de biografías que debían constituir un comentario a la primera década de Tito Livio. Además, es innegable que conceptos esenciales de la doctrina política de Machiavelli aparecen de forma reiterada en la obra de Malvezzi. Tal es el caso de la omnipotencia de la fortuna, que parece constituir la base de su doctrina polí-

11. Baltasar Gracián, Agudeza y arte de ingenio, cit., t. II, p. 198-199.

12. Giuseppe Toffanin, Machiavelli e il "Tacitismo", Napoli: Guida Editori, 1972 [1921]. Véase para el caso español José Antonio MARAVALL, «La corriente doctrinal del tacitismo político en España", Estudio de Historia del Pensamiento Español. Tercera Serie. El Siglo del Barroco, Madrid: Ediciones Cultura Hispánica, 1984, p. 75-98 y Enrique TIERNO GALVÁN, «El tacitismo en las doctrinas políticas del Siglo de Oro español», Escritos (1950-1960), Madrid: Tecnos, 1971, p. 13-93, y para el caso de Saavedra, véase André JouCla-RUAU, Le tacitisme de Saavedra Fajardo, París: Editions Hispaniques, 1977. 
tica («en los negocios políticos no hay otra regla que la fortuna»), ${ }^{13}$ o la evidente huella dejada por la ávida lectura de los Discorsi («Es el mismo aquel que estaba en la plaza, que el que está ahora en el Senado; más se mira con diferencia desde el senado a la plaza que desde la plaza al senado"). ${ }^{14}$ Basta escarbar un poco entre las líneas del marqués, para encontrar citas directas de Machiavelli o, lejos de aquel nombre maldito, la impronta de sus ideas. Podríamos decir, en suma, que gracias a las biografías de Malvezzi, en la piadosa corte de Felipe IV circuló el pensamiento del genial florentino.

Todavía puede ampliarse la pesquisa fontística en otra dirección que lleva a los entresijos del estilo y aclara su evolución futura. Es sabido que ya los traductores de Cornelio Tácito convirtieron su prosa en depósito de sentencias políticas, convencidos de que tenían un sentido predictivo del comportamiento político, práctica, por otra parte, derivada de la misma pedagogía humanista. ${ }^{5}$ Tal será la conducta de Allamos Barrientos en su traducción castellana de Tácito, por ejemplo. Virgilio Malvezzi sigue esa línea, pero incorporando las sentencias a una estructura narrativa que les confiere un más pleno sentido y un contexto preciso. La observación no es baladí, porque la literatura lacónica se encontrará siempre marcada por la tensión entre la estructura narrativa (biografía, historia, novela bizantina) y el repertorio de afirmaciones sentenciosas que conforman su textura. Lo sustancial del Romulo no consistía, pues, en el recorrido por una serie de hechos archisabidos de la historia de Roma, sino en el contenido político que era capaz de transmitir, y en la universalización a que sometía el sentido de su personaje histórico. Era historia y prontuario a un tiempo: había, detrás de Rómulo, un modelo de hombre. Si a Rómulo le quitamos el nombre propio, ya tenemos en pie El héroe del Padre Gracián. Que esa fuera la fuente del genial aragonés, lo demuestra su primera obra, que surge con naturalidad, como veremos, de la lectura de Virgilio Malvezzi. Basta dar un paso

13. El Rómulo, ed. cit., p. 80; es abrumador el predominio de la fortuna en Il Tarquinio superbo como fuerza ordenadora de la historia.

14. La cita reveladora se encuentra en Obras del marqués, ed. cit., f. 102. La distinción entre piaz$z a$ y palazzo como conceptos políticos es central en el pensamiento de Niccolò Machiavelli, por cuanto atañe a su pretendido republicanismo, y puede hallarse en los Discursos sobre la primera década de Tito Livio (I, 47): «De modo que, los que le habían oído hablar antes, cuando era un ciudadano privado, y le veían después en la suprema magistratura tranquilo y callado, pensaban que esto provenía, no de un mejor conocimiento de los asuntos, sino de que los grandes le habían engañado y corrompido. Y habiendo sucedido esto muchas veces y a muchos hombres, nació de allí un proverbio que decía: éstos tienen un ánimo en la plaza y otro en el palacio» (Nicolás MAQUIAVELO, Discursos sobre la primera década de Tito Livio, traducción, introducción y notas de Ana TARANCÓN, Madrid: Alianza, 2000, p. 153); "Costoro hanno uno animo in piazza, ed uno in palazzo" (Niccolò MACHIAVELLI, Le grandi opere politiche. II. Discorsi sopra la prima Deca di Tito Livio, a cura di Gian Mario ANSELMI e Carlo VAROTTI, Torino: Bollati Boringhieri, 1993, p. 181).

15. Véase una valoración del hecho con respecto al estilo de Gracián en Aurora Egido (ed.), Baltasar Gracián, El discreto, Madrid: Alianza, 1997, p. 40-46, o bien con respecto a Quevedo en Sagrario LÓPEZ POZA, «La erudición como nodriza de la invención en Quevedo", La Perinola, n. 3, 1999, p. 171-194. 
más para convertir la biografía lacónica del italiano en una colección sentenciosa desprovista de armazón narrativo. Esa evolución natural se cumple ya en el círculo de Lastanosa, donde la obra del formidable aragonés será sistemáticamente extractada. No se necesitaba para ello a Tácito o Séneca: se tenía a mano El discreto o El héroe. ${ }^{16}$ Tal será el destino de los productos del laconismo romance, recordando la tensión poética primordial entre sentencia y estructura.

Finalmente, pueden añadirse a nuestra compresión del estilo perspectivas propias del siglo XVII, y ausentes de la tradición literaria. Por ejemplo, la importancia creciente de la matemática como objeto de literatura, un aspecto subrayado recientemente, y con gran acierto, por Carlos Vaíllo. ${ }^{17}$ El hecho, en apariencia extraño, hermana el laconismo con los progresos evidentes de la matemática a lo largo del siglo XVI (la recuperación de Arquímedes, por ejemplo, una de las fuentes del primer Galileo), y que no harán sino acelerarse a lo largo del siglo XVII, hasta culminar, a finales de la centuria, en el cálculo infinitesimal, por no hablar de la pasión geométrica de la filosofía cartesiana. Tal característica deviene la mismísima evidencia en Il Tarquinio superbo, donde encontramos el estilo lacónico descrito en términos matemáticos:

El dar preceptos a los príncipes para reinar bien es empeño que toca en bizarría, si bien es sobradamente costoso y estoy por decir sobervio [...] Un punto que en abstracto se figura indivisible, en concreto se divide en muchas partes, y se puede dividir infinitamente, y así juzgo de más conveniencia a obra tal los ejemplos que los preceptos. ${ }^{18}$

Nótese, de pasada, cómo para el marqués la doctrina expuesta mediante una inteligible acumulación de sentencias hilvanadas en una estructura («los ejemplos»), tiene un valor superior al de la mera sentencia aislada, o a su simple sumatorio («los preceptos»), y que esa relación alcanza un sentido visual a partir de una comparación matemática que recuerda el cálculo infinitesimal. La obra biográfica se puede descomponer en sus sentencias como un punto de aparente indivisibilidad se puede subdividir infinitamente. La obra está plagada de tales expresiones, ${ }^{19}$ como también, aunque en menor medida, Il Romu-

16. Y siempre que no se quiera ver ahí una simple relación mecánica entre unas y otras obras; véanse las importantes observaciones de Emilio BLANCO en su edición de Baltasar GRACIÁN, Oráculo manual y arte de prudencia, Madrid: Cátedra, 1995, p. 21-23.

17. Véase Carlos VAíllo, «Imágenes matemáticas y economía del discurso en la Vida de Marco Bruto de Quevedo", en Jean-Pierre Étienvre (ed.), Littérature et Politique en Espagne aux siècles d'or, Paris: Klincksieck, 1998, p. 401-406.

18. Obras del Marqués..., ed. cit., f. 95. Como en este caso, en varias traducciones españolas, todas las obras traducidas de Malvezzi aparecen adjudicadas a Quevedo; véase José Simón DíAZ, «Los traductores españoles de Malvezzi», Revista de Literatura, n. XXVIII, 1965, p. 87-93, y El Rómulo, ed. cit., p. 15.

19. "Muchas líneas se enderezan a un punto, muchas sendas a un lugar determinado" (Obras, ed. cit., f. 95v), «quien muda el blanco es también necesario que mude el punto» (íbid., f. 101v), "mil puntos no comprenden una línea» (íbid., f. 109), "su afecto sea igualísimo a todas las partes de la circunferencia» (íbid., f. 212), etc. 
$l o .^{20}$ Se trata acaso de la parte más novedosa de un lenguaje político que no abandona sus tradicionales comparaciones médicas o astronómicas, pero que, a través de una nueva trama metafórica, se hace eco de la generalización de los descubrimientos geográficos o de la actualidad de las nuevas ciencias físicas. ${ }^{21}$ Hay en ese juego de lo lacónico una consistente y continuada metáfora con la nueva simbolización matemática que se consolida a lo largo del siglo XVII y que hoy nos resulta familiar, pero que venía a ser por entonces un lenguaje nuevo y una forma inédita de abordar la realidad empírica. Esa simbolización corre pareja con la síntesis significativa que los contemporáneos percibían en el emblema, y forma parte de la importante vertiente visual de la cultura del siglo XVII. Pero la importancia creciente del cálculo matemático es indicio de una más profunda ruptura que está en la base de los nuevos desarrollos literarios. Puede ligarse, por ejemplo, a las varias «crisis escépticas» que socavan los cimientos del pensamiento europeo ya en los últimos años del siglo XVI. ${ }^{22}$ En esa perspectiva, parece obvio preguntarse si la aproximación metafórica al mundo matemático no delata una avidez que desborda el mero posicionamiento retórico. Pero, en primera instancia, esa cascada de analogías matemáticas confiere a aquellas y otras parcelas del texto una «ilusión de exactitud» con la finalidad de «decir mucho en pocas palabras" y también "para propiciar un juego deliberado de desvelamientos y omisiones», un estilo que busca, en palabras de Borges, «una ilusoria exactitud», ${ }^{23}$ y quizá por ello se detecta fácilmente tanto en Quevedo como en Baltasar Gracián. ${ }^{24}$ Ese nuevo estilo depuraba la tradición dando un lugar a las exigencias de los nuevos tiempos. Escribir a lo del marqués Virgilio Malvezzi, como dirá Uztarroz a propósito de Gracián, constituía un clasicismo renovado que miraba al futuro en idéntica medida que al pasado venerable de la tradición literaria. No es extraño que los testimonios del hondo interés que despertó Malvezzi en la corte de Madrid emerjan con evidencia a poco que se rastree en la documentación. Para observar tal reacción con claridad y concreción, interesa resaltar la relación entre Saavedra Fajardo y Francisco de Quevedo, y añadir una breve reseña de Mártir Rizo.

Muchos de los aspectos comentados debió de percibir Francisco de Quevedo en Il Romulo cuando casi sin solución de continuidad se embarcó en su traducción. Ese adentrarse en el laconismo biográfico marca un momento clave

20. «Dezía un philósopho que Dios era geómetra, quizá porque el mundo consiste en proporción más geométrica que arismética" (El Rómulo, ed. cit., p. 55)

21. "Es el humano un poder muy parecido al viento» (Obras del Marqués..., ed. cit., f. 103), «la bondad del principado no consiste en un punto indivisible: es fuerza darle la latitud que le convenga» (íbid. f. 95v), "pescamos solos en este océano, quien pesca un mugil, quien una ballena» (íbid. f. 114v).

22. Véase Richard H. POPKIN, La historia del escepticismo desde Erasmo hasta Spinoza, México: Fondo de Cultura Económica, 1983.

23. Carlos Vaíllo, art. cit., p. 506.

24. Carlos Vaíllo, art. cit., y Benito Pelegrín, «Rhétorique du silence: $\mathrm{X}=\mathrm{S}+\mathrm{Z}$ », en Les formes brèves (I Colloque International), Aix-En Provence: Université de Provence I, 1984, p. 65-90. 
en la evolución de su estilo. ${ }^{25}$ Además, don Francisco debió de ver en el laconismo malvezziano el ejemplo de una práctica literaria que él mismo había experimentado a partir de la agudeza de su carácter y de su palabra: el estilo lacónico, en suma, valía como formulación más clásica y acabada de una inclinación personal. Recordemos que la tensión entre expresión y estructura literaria se revela problemática ya en su juventud en el Buscón: ${ }^{26}$ la demorada atención al detalle de la expresión aguda delata en esta perspectiva un rasgo personal. ${ }^{27}$ Recordemos, también, el descoyuntamiento de sus figuras satíricas, que concluyen en el gesto servido por la chispeante expresión o en la disgregación en una serie de imágenes cuya esencial desconexión es amplia base de la sátira. Prácticas literarias en las que don Francisco se nos muestra hábil explorador desde comienzos de la centuria, pero que se ennoblecían con los nuevos referentes clásicos. Y todavía podemos apurar ese interés desde otros ángulos convergentes con los anteriores. Su traducción de Virgilio Malvezzi delata la búsqueda de un clasicismo alternativo al florido gongorismo no menos que sus ediciones de obras clásicas de la poesía quinientista. Virgilio Malvezzi podía ser antídoto contra el cordobés, como lo fueron fray Luis de León, Francisco de la Torre o San Juan de la Cruz, los dos primeros editados o con dedicatoria de $1631 .{ }^{28}$ En fin, tenía, por lo que se va viendo, variados y sobrados motivos para la identificación estética y personal con la prosa lacónica.

Como decimos, parece ser que su traducción del Romulo fue emprendida casi de inmediato: la Aprobación la firma fray Juan Maldonado el 20 de julio de 1632; la licencia, Martín de Uribarri el 9 de agosto siguiente. Esa primera edición no se hizo con el beneplácito de Quevedo, según se deduce, entre otras cosas, de una nota del impresor navarro en la que afirma: «Mal trasladado vino a mis manos este libro, leíle yo, fui curioso, dile a la imprenta por ser liberal». ${ }^{29}$ Más aún, en realidad Quevedo había ultimado la traducción en el verano de 1631, como demuestra la dedicatoria, extendida en Madrid el 2 de septiembre de 1631. Si tenemos en cuenta que la edición príncipe de Il Romulo aparece en Bolonia en 1629, no podrá no sorprender la rapidez de reflejos de su traductor: apenas podemos conceder unos meses para la circulación y el general conocimiento de la primera edición italiana. Durante el año treinta Il Romulo debió de hacer furor en la corte de Madrid: un año después ya Francisco de Quevedo había ligado a él su nombre, y lo que es más importante, había encabezado su traducción con un encendido elogio de la obra del marqués.

25. María Luisa López GrijerA, «La prosa de Quevedo en los sistemas elocutivos de su época», en Quevedo in perspective, Newark (Delaware): Juan de la Cuesta, 1982, p. 81-100.

26. Fernando LÁZARO CARreter, "Originalidad del Buscón», en Francisco De Quevedo, La vida del Buscón, ed. de Fernando CABO, Barcelona: Crítica, 1993, p. IX-XXIV y Francisco Rico, La novela picaresca y el punto de vista, Barcelona: Seix Barral, 1989, p. 120-129.

27. Véase Maxime CHeVAlier, Quevedo y su tiempo: la agudeza verbal, Barcelona: Crítica, 1992.

28. Véase Pablo Jauralde Pou, Francisco de Quevedo (1580-1645), Madrid: Castalia, 1998, p. $588-593$.

29. Véase El Rómulo, ed. cit., p. 15-16. 
De hecho, el nombre de Quevedo se ha relacionado con diversas traducciones de Virgilio Malvezzi no siempre suyas. ${ }^{30}$ Sin duda porque aquel estilo era emblemático: una llave para abrir puertas en la república literaria como indiscutible señal de calidad. Por otra parte, Quevedo se encuentra en ese momento muy próximo a los círculos del poder cortesano en cuanto afamado propagandista del Conde Duque. Su traducción de Virgilio Malvezzi debió de hacer, por tanto, mucho para poner de moda al italiano entre los escritores españoles. Ese entusiasmo de Quevedo se trasluce en el prólogo $A$ pocos con que nos presenta la obra del marqués, «la pluma más feliz de Italia» ${ }^{31}$ Nos habla del nuevo Rómulo como de una feliz construcción ("parto no de Rhea, sino del ingenio, alimentada no por una loba, sino por el estudio»), y cifra el hallazgo del marqués en haber superado el mero recuento de una historia: «Escribieron la vida de Rómulo muchos, mas a Rómulo ninguno». Valor supremo del estilo consiste en aclarar las razones de sus actuaciones políticas, insuflándole un alma a los meros datos de la historia («los pasados fueron historiadores de su vida, nuestro autor de su alma»), de donde se extrae un modelo de actuación política («el Marqués escribe el príncipe, los demás el hombre») que está implícito en la historia que cuenta y que el comentario pone de manifiesto («Refiérese lo que vieron todos, y lo que él procuró, si fuese posible, que no se viese»). Se trata, como vemos, de una suma de aciertos que tiene por intermediario el estilo lacónico («un libro donde es inmensa la escritura y corta la lección»); tras lo cual Quevedo daba la palma al marqués de Malvezzi («obligación es admirarle, y locura competirle»). Poco puede extrañarnos, así, que en 1632 el escritor español iniciase, como parece plausible, la redacción de su Marco Bruto, publicado en 1644..$^{32}$

Otro dato de no menor importancia, y convergente con el anterior, nos pone sobre la misma pista: la evolución de Diego de Saavedra Fajardo. Don Diego fue uno de los políticos españoles más importantes de la época como embajador español en Italia y Centroeuropa. Como tal visitó en diferentes ocasiones la corte de la Madrid, donde tendrá residencia fija desde 1643. Entre sus tareas diplomáticas italianas y su envío como principal embajador de Felipe IV en el Imperio, pasará algunos meses en Madrid, donde llega en septiembre de 1630. ${ }^{33}$ De muy poco después, del 1 de febrero de 1631, data la composición de las primeras obras que se nos han trasmitido con su nombre. ${ }^{34}$ Esas dos

30. José Simón DíAZ, art. cit.

31. El Rómulo, ed. cit., p. 109, y el prólogo de Quevedo en p. 105-106 (1632) y 108-109 (1635).

32. Bruce W. Wardropper, Siglo de Oro: Barroco en F. Rico, Historia y crítica de la literatura española, Barcelona: Crítica, 1983, III, p. 542.

33. De acuerdo con la datación de la estancia de Saavedra en Madrid que establece Quintín Aldea VaQuero, Europa y España en el siglo XVII. La correspondencia de Saavedra Fajardo. Tomo I, 1631-163, Madrid: CSIC, 1986, p. 3. El dato puede verse en Diego DE SAAVEDRA, Introducciones a la política y Razón de estado del rey católico don Fernando, ed. de Alberto BLECUA y Jorge García López, Barcelona: Asociación de Bibliófilos de Barcelona, 1984, p. 71.

34. Teniendo en cuenta que la primera redacción de República literaria probablemente no es suya, tal como ha demostrado Alberto BLECUA, «Las Repúblicas literarias y Saavedra Fajardo», El Crotalón. Anuario de la Filología Española, n. I, 1985, p. 67-97. 
obras, no publicadas en su momento, son las Introducciones a la politica y la Razón de estado del rey don Fernando el Católico: ambas conservadas en un manuscrito que solo modernamente ha visto la luz permitiendo observar, a través de estas semillas, la génesis y el proceso de su posterior evolución como escritor. En las Introducciones a la política nos encontramos con un pequeño comentario de la Política de Aristóteles donde Saavedra va desgranando temas clásicos de la política aristotélica. Muy diferente resulta la Razón de estado, que se adentra con paso firme en el laconismo a la moda, extractando párrafos de la Historia de Mariana y comentando la vida de Fernando el Católico. Lo que ahora nos interesa es la distancia estilística y estructural que corre entre ambas obras: las Introducciones a la política parecen mirar al pasado, a los comentarios académicos; no logran soslayar una perspectiva que roza el anacronismo, y constituye, según creo, un experimento literario fallido. La Razón de estado, en cambio, nos sitúa en pleno laconismo biográfico. Notemos, además, que las dos obras de Saavedra Fajardo iban dirigidas al Conde Duque de Olivares en la epístola con que se abría el manuscrito, si bien la cosa no pareció tener efecto sobre el poderoso privado. ${ }^{35}$ Ambas permanecieron manuscritas, pero nos dicen mucho, según creo, acerca de la creciente importancia del laconismo literario en la corte de Madrid a finales de 1630. Saavedra llega a la corte en ese septiembre de 1630: cuatro meses después, el 1 de febrero de 1631, ya tiene ultimada una biografía lacónica de Fernando el Católico, que no puede ser sino el reflejo de la pujante fortuna de Malvezzi. Pocos meses después, en septiembre de 1631, Francisco de Quevedo firma ya la dedicatoria de su traducción, que se estampará al año siguiente. Parece evidente que a lo largo de ese año crucial la obra de Malvezzi hizo furor en la Corte de Madrid, si hombres tan cercanos al CondeDuque como Quevedo y Saavedra Fajardo, se embarcaron en su traducción o en su directa emulación. En 1631, podemos dar por sentada una auténtica competición cortesana para escribir obritas políticas en estilo lacónico; era una extraordinaria novedad y un nuevo lenguaje literario cortesano. No es difícil sospechar maniobras políticas detrás de ese ansia de emulación. La obra debía de ser del agrado del Conde-Duque, quien años después llamará a Virgilio Malvezzi a Madrid: escribir en estilo lacónico parecía resultar, en suma, un ventajoso ejercicio cortesano. En el entorno del Conde Duque, política y literatura andaban de la mano, y ahí se ha querido ver, en ocasiones, un paralelismo inverso con la acogida dispensada a Marino en la corte francesa. En cualquier caso, el laconismo hispánico irradió desde la corte, donde ya se hallaba Virgilio Malvezzi en 1636, y donde acabará ejerciendo funciones de cronista. Escritor admirado desde la publicación de Il Romulo, sin duda aspiraba a elevados puestos cortesanos en Madrid, cosa que conseguirá con Il ritratto del privato politico cristiano: ${ }^{36}$ un elogio del Conde Duque que le abrirá también las puertas de la corte Habsburgo, donde, según contará años después, se encontraba a sus anchas:

35. Alberto Blecua y Jorge García López, ed. cit., p. 71.

36. Eduardo TODA y GÜELl, Bibliografia espanyola d'Italia, Castell de Sant Miquel d'Escornalbou: Imp. Vidal Guell, 1927-1931, III, p. 9, y Tommaso BozZA, op. cit., p. 180. 
"Quivi ho goduto i giorni sereni, gli ozii felici, i negoci securi, gli studii premiati». ${ }^{37}$ No es, pues, arriesgado suponer que en 1630, apenas llegado don Diego a Madrid, Il Romulo debía no sólo estar de moda, sino ser del gusto del astro dominante de la corte, el Conde Duque de Olivares. Eso explica que el escritor aplicara de inmediato el procedimiento a la vida de Fernando el Católico, obra escrita a lo del marqués Virgilio Malvezzi, dejando a un lado sus Introducciones a la política. Tampoco es arriesgado imaginar que estuviera al corriente de la traducción quevediana del Romulo, concluida, como sabemos, a finales de la primavera de 1631 .

Sin embargo, la impronta de la obra de Malvezzi en Saavedra Fajardo no se limita a esa primera obra, inédita, de 1631, sino que será la base estructural y literaria de su obra mayor, las Empresas politicas, publicadas por primera vez en 1640 y rehechas con significativas diferencias en $1642 .{ }^{38}$ Ello hasta el punto de que don Diego trasladó páginas enteras de la Razón de estado del rey católico don Fernando a los capítulos de su nueva obra, encabezados por un emblema comentado. Todo indica, en suma, que la biografía política constituye la base de las Empresas politicas; y por si fuera poco, la obra aparece acompañada por una carta laudatoria de Herycius Puteanus, discípulo de Justo Lipsio, con la cual don Diego cerraba el círculo del estilo lacónico, invocando como índice de calidad a su mismo apologeta europeo. ${ }^{39}$ De su comentario aristotélico a la figura ideal del príncipe cristiano, la evolución de Saavedra demuestra fehacientemente que esas biografías lacónicas fueron vehículos ideales de la tratadística política.

Otro testimonio interesante en tal sentido lo constituye Pablo Mártir Rizo, escritor cortesano de libros políticos y biografías que mantenía por entonces relaciones de amistad con Francisco de Quevedo. No era la primera biografía que escribía cuando a principios del verano de 1632 presentó a la aprobación su Vida de Rómulo. Como en otros casos, es interesante fijarnos en las fechas de aprobaciones y dedicatorias, que en Mártir Rizo delatan un conocimiento cercano de la traducción de Quevedo. Pero ahora el problema se nos plantea con paladina sencillez. No tenemos que descubrir ninguna relación entre obras o autores, simplemente debemos dejar hablar a Mártir Rizo:

La alabanza con exceso que vi dar a un grande ingenio al Rómulo del marqués Virgilio me dio a mí motivos para escribir su vida, por ver si había en España quien la pudiese igualar, porque según el parecer de la persona que digo, ni aun en el mundo se podía hallar obra que compitiese con la suya. ${ }^{40}$

37. Tomo la cita de Donald L. SHaW (ed.), V. MALVEZZI, Historia de los primeros años del reinado de Felipe IV, London: Támesis, 1966, p. XI.

38. SAAVEDRA se retracta del tacitismo de la primera versión; véanse Jorge GARCÍA LóPEZ, «Saavedra y Quevedo: dos perfiles del seiscientos», La Perinola. Revista de investigación quevediana, n. 2, 1998, p. 237-260, y Diego DE SAAVEDRA FAJARDO, Empresas políticas, ed. de Sagrario LÓpez POZA, Madrid: Cátedra, 1999, p. 88-107.

39. Puede verse el texto en SaAvedra Fajardo, Empresas políticas, ed. cit., p. 187-192.

40. José Antonio Maravall (ed.), Pablo Mártir Rizo, Norte de príncipes y Vida de Rómulo, Madrid: Centro de Estudios Constitucionales, 1988, p. 117. 
Ese grande ingenio y ese parecer de la persona que digo bien podría ser, en mi opinión, el mismísimo Francisco de Quevedo, y si tal identificación puede suscitar alguna duda, la despeja el razonamiento desarrollado a continuación, donde el propio Mártir alude a la traducción de Quevedo: «Dirán algunos que ha sido exceso escribir yo materia que ha tratado tan gran varón, con aprobación de tantos grandes ingenios y ahora mejorada en la traducción de don Francisco de Quevedo, que la habrá dado nuevo lustre en nuestro idioma». ${ }^{41}$ Ahora el grande ingenio de que nos hablaba antes se ha convertido en la aprobación de tantos grandes ingenios, y la obra de Mártir parece no querer ir más allá de la emulación literaria servida con ejemplos de la Poética; pero cada afirmación del prólogo acaba siendo una alabanza implícita de Virgilio Malvezzi, motivo de aplauso general y objeto de competitiva emulación, reiterado en obras y prólogos posteriores hasta llegar al Discreto o El criticón. ${ }^{42}$

Vayamos, pues, a Baltasar Gracián. La obra del jesuita repite puntualmente el camino que acabamos de trazar, aunque de la obra lacónica escueta hemos de pasar a más amplios planteamientos literarios. Su producción literaria se inicia con El héroe (1639, pero primera ed. 1637), prosigue con El político (1640) y culmina con El discreto (1646). Ahí es posible encontrar ya un primer paralelismo con Virgilio Malvezzi en la proyección de obras nunca escritas o finalmente rehechas con otros títulos, ya que la biografía lacónica se revelaba como un esquema literario de gran flexibilidad. ${ }^{43}$ Sin embargo, Gracián introduce novedades que delatan al creador de raza. Si en los ejemplos anteriores de Quevedo o Saavedra Fajardo podemos deslindar el cuidadoso seguimiento de Virgilio Malvezzi, mediante la traducción inmediata o la imitación, en el caso de Baltasar Gracián asistimos desde el comienzo a un evidente salto cualitativo: el estilo lacónico ha encontrado a su hombre. En la prosa de Gracián percibimos, de hecho, sin esfuerzo al escritor que se apropia de una fórmula en boga y la hace suya. Ejercicio a la altura de la categoría y la idiosincrasia del aragonés y envite sin duda aplaudido en el ambiente de refinamiento intelectual que rodeaba a Lastanosa. Tal sucede con El héroe (1637), que ya desde el principio evita el escueto planteamiento histórico para presentarnos un modelo humano que constituye la generalización del pesimismo como norma de conducta; $y$, sin embargo, por debajo de los entresijos del héroe gracianesco, se trasluce Malvezzi, que ya había apostillado con tal sustantivo a su Rómulo romano («Algunos le dieron el nombre de héroe, la verdad lo llamó Dios» ${ }^{44}$ ), cosa evidente para ciertos contemporáneos, que colocaban El héroe junto a El político como

41. José Antonio Maravall, ed. cit., p. 118.

42. "Barclayo [...] apasionadamente condena a barbaridad la española llaneza en sus escritores» nos dice en el prólogo $A$ los lectores don Vincencio Juan de Lastanosa (aunque posiblemente escrito por el mismo Gracián). Véase Aurora EGIDO, ed. cit., p. 158-159.

43. Malvezzi quería escribir un ciclo literario sobre héroes de la antigüedad romana, programa comparable a algunas obras no escritas de Baltasar Gracián como, por ejemplo, el Ministro real. Véase Miguel BATLLORI, ed. cit., p. 175.

44. El Rómulo, ed. cit., p. 52. 
cualquier espejo de príncipes (así, por ejemplo, Salinas en la aprobación de $E l$ discreto). ${ }^{45}$ Que el héroe gracianesco surja con naturalidad de la meditación literaria sobre Il Romulo, lo demuestra el cotejo entre la prosa del italiano y las incomprensibilidades de caudal del mundo gracianesco: "No deben los príncipes dejarse medir. Bajarse a la comparación sin seguridad de vencer, es seguridad de perderse. Un no sé qué más que en los otros se desea en quien tiene un no sé qué más que los otros». ${ }^{46}$ Es la prosa de $I l$ Romulo, pero ya palpita la doctrina y el estilo de El héroe de Gracián.

Esa evidente cercanía entre ambas obras la encontramos también en las declaraciones de los contemporáneos del aragonés. Testimonios elocuentes son dos cartas de don Juan Francisco Andrés de Uztarroz donde consigna, con varios días de diferencia, sus impresiones de la lectura del Héroe. La primera la envía a don Vincencio Juan de Lastanosa el 2 de septiembre de 1637, y en ella da noticia de la publicación del libro: «Los días pasados me dio... el amigo Juan de Gárriz El héroe de Lorenzo Gracián». ${ }^{47}$ La crítica allí vertida contra el estilo gracianesco parece opinión sincera, expresada en la intimidad epistolar, aunque unida al deseo visible de no llevarla hasta el final. Por lo visto, al doctor Andrés de Uztarroz le dejaban perplejo las peculiaridades estilísticas de la obra y utiliza a modo de navaja de Ockam el Dum brevis esse laboro horaciano: "porque siempre el estilo lacónico suele tener algunos celajes de obscuridad, como lo advirtió Horacio en su Arte poética: Dum brevis, etc.». En efecto, Uztarroz utiliza la cita horaciana no como piedra de toque del virtuosismo del nuevo estilo, tal como hará Saavedra al frente de sus Empresas politicas, en una suerte de torneo con la antigüedad, ${ }^{48}$ sino como un juicio personal circunscrito al círculo de Lastanosa. La actitud prevenida de Uztarroz hacia la primera obra de Gracián, cuando después firmará la aprobación de algún otro libro suyo, como, por ejemplo El político o El discreto, dice mucho sobre la novedad del estilo y las dificultades que tuvo para afirmarse en un principio. La referencia horaciana era conquista de los modernos en el caso de Saavedra; un antídoto contra la nueva forma expresiva, en el de Uztarroz. Sin embargo, como nos declara el mismo Gracián en el prólogo de El discreto: «no echaron a perder Aristóteles ni Séneca las dos lenguas, griega y latina, con su escribir recóndito». ${ }^{49} \mathrm{El}$ Arte poética retrocedía ante el ejemplo del Estagirita unido a modelos imperiales.

En la segunda epístola, fechada pocas semanas después, el 22 de septiembre de 1637, Andrés de Uztarroz se dirige a don Francisco Jiménez de Urrea en estos términos:

45. Llama la atención sobre el hecho Aurora EGIDO, ed. cit., p. 150, n. 9.

46. El Rómulo, ed. cit., p. 52.

47. Cito por Ricardo DEL ARCO, La erudición aragonesa en el siglo XVII en torno a Lastanosa, Madrid: Cuerpo de Archiveros, 1934, p. 94.

48. Y por tanto, ateniéndose al tópico humanista de antiguos y modernos. Véase el texto en Sagrario López POZA, ed. cit., p. 176.

49. Aurora EgIDO, ed. cit., p. 159. 
Estos días ha publicado este caballero un librito, dedicándoselo al rey. El folio es de 16, escrito a lo del marqués Virgillio Malvezzi. ${ }^{50}$

La cita suele esgrimirse para resolver la complicada cuestión de la dedicatoria de esa primera edición desaparecida de El héroe, que debe adjudicarse a Felipe IV, como aquí nos asegura Uztarroz, o quizá al propio don Vincencio. Más interés tiene el remate de la cita, donde Andrés de Uztarroz identifica la simiente literaria de El héroe en la prosa de Malvezzi ("escrito a lo del marqués Virgillio Malvezzi»).

Este recorrido a través de las tempranas reacciones ante El héroe nos pone sobre la pista de El político don Fernando El Católico (1640): una obra con la que Gracián celebró la figura histórica del fundador de la monarquía española, y que es también admirable ejercicio retórico de prosa emblemática, cuasi visual. ${ }^{51}$ En su brillante exordio, donde el aragonés nos muestra su posición con respecto a obras clásicas del género político, pone en evidencia, por ejemplo, la distancia que lo separa de Jenofonte con argumentos esgrimidos desde comienzos de siglo. ${ }^{52}$ Pero si rechaza el ejemplo de Ciro, no hará lo mismo con el de Rómulo: «Fue Rómulo prodigio de la capacidad y del valor...»; una referencia que a la altura de 1640 no podía entenderse sino como inequívoco elogio de la obra de Malvezzi, quizá leída ya en la traducción de Quevedo. La elección no es, por tanto, entre dos ejemplos históricos, sino entre dos modalidades literarias del biografismo político: la dilatada abundancia de Jenofonte, autor tan caro a Machiavelli, y la política brevedad de Virgilio Malvezzi. Esa opción literaria resulta todavía más evidente si comparamos los textos del español y el italiano situándolos en paralelo. ${ }^{53}$

no tanto cuerpo de su historia, cuanto alma de su política (Gracián, El político, 276a) los pasados fueron historiadores de su vida [de Rómulo], nuestro autor de su alma [...] Llámase Rómulo, no Historia u Vida de Rómulo (El Rómulo, p. 105, prólogo de Quevedo A pocos)

los hechos de los príncipes tienen antes

Fueron comúnmente tan prodigiosos los hechos de todos los fundadores, que las narraciones dellos se juzgaron antes por invenciones de la épica que por rigores de la historia (Gracián, El político, 276b)

los suyos los imaginaron más que hombres, hasta inaugurarlos en dioses; los estraños, echando por otro estremo, los tuvieron por héroes fabulosos (Gracián, El político, p. 276b) otro cualquier semblante que el verdadero.

El contarlos como parecen tiene de lo épico; como son, de lo satírico (El Rómulo, p. 46)

Tiene el príncipe un no sé qué más que hombre en la majestad del semblante, en los ángeles que le defienden, en las estrellas que le influyen. Algunos le dieron nombre de héroe, la verdad lo llamó dios (El Rómulo, p. 52).

50. Miguel BATllori, Baltasar Gracián en su vida y en sus obras, Zaragoza: Instituto Fernando el Católico, 1969, p. 47, la cursiva es mía.

51. Véase el clásico y brillante estudio de Angel Ferrari, Fernando El Católico en Baltasar Gracián, Madrid: Espasa Calpe, 1945.

52. Cfr. Miguel BatLlori, ed. cit., p. 276b.

53. A fin de evidenciar las semejanzas entre los pasajes de Gracián y la versión de Quevedo, como en los casos anteriores, cito la obra de Malvezzi por la traducción quevediana del 
Este llamativo paralelismo, no señalado nunca antes, según creo, converge con el testimonio contemporáneo de Andrés de Uztarroz y nos conduce al origen de esas primeras biografías de perfiles político-morales de Gracián, conformadas sobre el paradigma lacónico del Romulo malvezziano.

De forma complementaria, quizá no sea del todo ilícito ver en esas primeras obras de Baltasar Gracián la consciente emulación de la lejana y extraña corte castellana. En El héroe se impone una consciente variación literaria en cada uno de sus veinticinco primores, reunidos bajo un título alusivo, descubriendo una manifiesta voluntad de variación literaria. La biografía lacónica podía tener desarrollos equivalentes o paralelos a los históricos o bíblicos tan de moda entre los escritores cortesanos de Madrid: Il Romulo, Marco Bruto, Davide perseguitato, etc. Esa voluntad de estilo y de hacer literatura, se multiplica en El discreto, donde cada discurso se nos presenta como variación dentro de un género literario o retórico distinto. "Razonamiento académico», "Crisis», "Apología», y así hasta sus precisos veinticinco «ejes del lucimiento discreto». Muy poco discreto, por cierto, en su detallada y minimalista exuberancia, en su misma consciente y evidente superioridad intelectual: veinticinco lecciones para los escritores cortesanos que rodeaban al Conde-Duque, rendidos amantes del laconismo político. Y asimismo, microcosmos y manual de estilo. Lección y norte, en suma, de una modalidad expresiva que se proponía como clasicismo literario. Malvezzi o Quevedo se querían o sabían Lipsios o Tácitos en romance, y entre los novísimos maestros, acaso superior a sus modelos, y aún a los antiguos, el mismo Baltasar Gracián.

Virgilio Malvezzi no inventó lo scrivere succoso, pero la vía romance que inauguró en Il Romulo se alzó de inmediato como estandarte y ejemplo de un estilo, a causa de una dilatada serie de aciertos paralelos y convergentes, que hicieron de esa biografía puntal el eje sobre el que podía pivotar toda una visión del mundo. En el caso español, el estilo lacónico y sentencioso se difunde a través de la circulación de la obra malvezziana en la corte madrileña: fue un estilo desarrollado a la sombra del grupo de intelectuales que rodeaba al Conde Duque de Olivares. En un momento posterior, como estilo de éxito, alcanzará ambientes más amplios y géneros literarios tales como la historia (Saavedra en su Corona gótica o Manuel de Melo en su Historia de la separación y guerra de Cataluña), el relato culto (Gracián en El criticón) o, en fin, la didáctica moral (Gracián en su Oráculo manual). En el principio de esa evolución literaria, nos encontramos con la biografía política malvezziana. Más que un episodio lateral de la posteridad del ciceronianismo se revela, pues, como peldaño necesario para clasicismos posteriores. Como en su tiempo delata el renombre europeo de Virgilio Malvezzi, cuyas obras se degustaban con avidez. Y no menos la universalidad literaria de Baltasar Gracián.

Romulo en la brillante edición de Carmen Isasi; indico directamente la página distinguiendo si se trata de texto traducido por Quevedo o añadido por él en forma de prólogo. 